\title{
A Comparative Study on Vertical Dynamic Responses of Three Types of Elevated Railway Tracks Subjected to a Moving Train
}

\author{
Li Shi $\mathbb{D}^{1}{ }^{1}$ Xiaoqiang Ye, ${ }^{1}$ Pengfei Zhang, ${ }^{2}$ and Lin Guo ${ }^{3}$ \\ ${ }^{1}$ College of Civil Engineering and Architecture, Zhejiang University of Technology, Hangzhou 310014, China \\ ${ }^{2}$ CCCC Highway Consultants Co., Ltd., Beijing 100088, China \\ ${ }^{3}$ College of Civil Engineering and Architecture, Wenzhou University, Wenzhou 325035, China
}

Correspondence should be addressed to Li Shi; lishi@zjut.edu.cn

Received 8 May 2019; Revised 8 July 2019; Accepted 4 August 2019; Published 25 August 2019

Academic Editor: Nhon Nguyen-Thanh

Copyright ( $92019 \mathrm{Li}$ Shi et al. This is an open access article distributed under the Creative Commons Attribution License, which permits unrestricted use, distribution, and reproduction in any medium, provided the original work is properly cited.

\begin{abstract}
A theoretical model incorporating the moving train, the railway track, and the elevated viaduct is established and then solved using periodic theory in this paper. The vertical wheel/rail forces and the dynamic responses of track and viaduct girder are obtained and compared for three different types of tracks, i.e., the double-block ballastless track, the rubber-pad floating slab track, and the steel-spring floating slab track. It is observed that the rubber-pad and steel-spring floating slab tracks can reduce more than $10 \%$ of the wheel/rail force and the reaction force at girder supports, when compared to those of the double-block ballastless track. Especially, the steel-spring floating slab track develops an uplifting force larger than the installation force of the fastening clip, which may cause failure of the rail fastening system.
\end{abstract}

\section{Introduction}

Due to the ever-increasing demand on public transportation services, China has seen a rapid development of urban rail transit (URT) lines in its major cities, e.g., Beijing, Shanghai, Nanjing, and Hangzhou. A large part of URT lines run underground, i.e., the metro lines. However, for areas deposited of mega-thick soft soils, the ground condition would be too weak [1] to construct a tunnel since the stability of tunnel face and the ground settlement during and after the tunnel construction are very hard to control. Alternatively, the URT can be elevated to surpass soft soil areas. The elevated bridge along with its overlying railway tracks are supported by the pile foundations, which is a common countermeasure to post-construction settlement suggested by the industry.

Since the urban space is very limited, URT lines would inevitably run closely to existing residential areas and vibration-sensitive facilities (e.g., hospitals and high-tech equipment). Public concerns continuously arise on environmental vibrations eradiated by the elevated URT lines
[2]. Since the railway track serves as a crucial part [3] on the vibration transmission path from the wheel/rail to the vibration-sensitive receiver (e.g., the ground, the building, and the equipment), truck structures of vibration reduction function (e.g., the rubber-pad floating slab track and the steel-spring floating slab track) are recommended over the commonly adopted double-block ballastless track.

The double-block ballastless track is mainly composed of (from top to bottom, as shown in Figure 1) the rail, the rail fastening system, the double-block sleepers, and the concrete slab. The segmental concrete slabs are cast in place to connect the precast sleepers and the bridge girder, i.e., the concrete slabs together with the double-block sleepers are rigidly bounded to the bridge girder.

Main components of the rubber-pad/steel-spring floating slab tracks (see Figure 2) are similar to those of the doubleblock track except that there is an additional rubber/spring layer between the concrete slab and the bridge girder. In this sense, the slabs are "floating" on the girder via the rubber/ spring layer, i.e., they are no longer bonded to the bridge girder. The rubber/spring layer of its resilient and damping features 


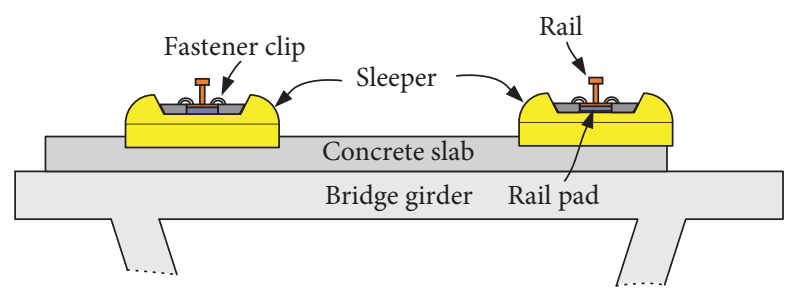

FIgURE 1: Schematic cross section view of double-block ballastless track.

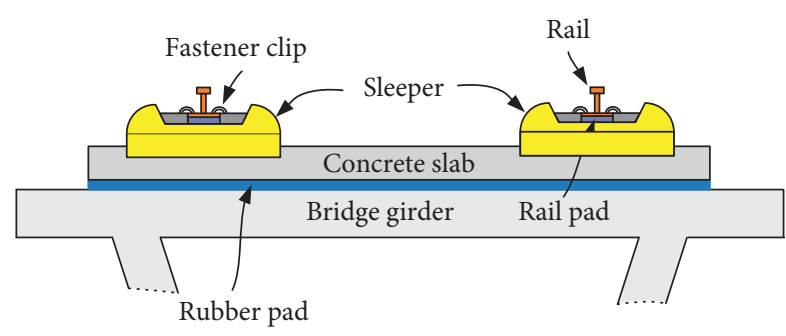

(a)

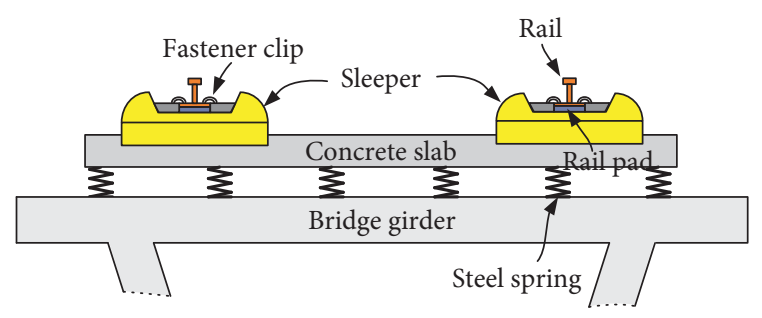

(b)

Figure 2: Schematic cross section view of floating slab track. (a) Rubber-pad floating slab track. (b) Steel-spring floating slab track.

can help attenuating vibrations, which are sourced from the wheel/rail interactions and then transmitted to the bridge, the foundation, and the nearby facilities.

Analytical, numerical, and field test studies have been carried out in the literature in order to evaluate the vibration-reduction effectiveness and then to optimize dynamic properties of the slab track. A three-dimensional (3D) vehicle-track coupled dynamics model was proposed and solved in time domain by Zhai et al. [4]. Both the traditional ballasted track and the nonballasted slab track can be simulated. Zhu et al. [5, 6] developed and tested a new type of slab track of vibration mitigation function especially within the low frequency range, i.e., $9 \sim 16 \mathrm{~Hz}$. Cui and Chew [7] illustrated the effectiveness of floating slab track through a comparison with the fixed slab track system. Lombaert et al. [8] established a 3D numerical model for the investigation of effectiveness of a resilient-mat floating slab track on the control of ground-borne vibrations. A field test was carried out by Dere [9] to evaluate the effectiveness of vibration reduction for the floating slab track. The steelspring floating slab track was suggested by $\mathrm{Ma}$ et al. [10] on controlling vibrations of overlying historic architecture generated by metro lines. For elevated railway tracks, Xin and Gao [11] found that bridge vibrations could be reduced by inserting a resilient layer between the slab track and the bridge girder. For a more comprehensive review on effectiveness of the floating slab track, one is referred to the review paper by Connolly et al. [12].

It is already clear that the floating slab track with the insertion of resilient layer (rubber or steel spring) is effective in reducing environmental vibrations when parameters of the resilient and damping parts of the track are carefully selected. However, as being pointed out by Jee et al. [13], the adoption of floating slab track for environmental vibration control may cause concerns about track damages since vibrations between the slab bearing and the loading (i.e., the train wheels) are enlarged. For example, the rail uplift ahead of the wheel would generate additional forces into the rail fasteners [14]. The failure of fastener renders stress concentration in neighboring units of the slab track, which makes the working conditions even worse [15].

It is noted that the above-mentioned studies on the vibration reduction effect of slab tracks are mainly for railway lines at grade. However, when the railway lines are elevated, the train-track-bridge dynamic interaction problem arises. Dinh et al. [16] established a 3D model for analyzing bridge-high-speed train interactions with due considerations on advanced wheel-rail contact model. The elastic effects of track and relative displacement between the track and the bridge deck are neglected. A fundamental model was proposed and then improved by Zhai et al. $[17,18]$ for analyzing the train-track-bridge dynamic interactions. Both the ballasted track and the nonballasted slab track have been considered in their model. For a recent stateof-the-art review on train-track-bridge dynamic interactions, one is referred to the paper by Zhai et al. [19]. Actually, as being concluded by them, the elastic effects of track are not always taken into account in bridge dynamic modeling. Especially, in viewing of modeling environmental vibrations induced by trains moving on elevated tracks, existing studies generally adopt over-simplified track models by either neglecting the elastic track components (e.g., the rail is connected to the bridge deck directly [20]) or by integrating the elastic properties of the track directly into the bridge [21].

To this aim, a periodic unit of three layers of beam that simulates the rail, the slab, and the bridge girder, respectively, is proposed and solved analytically for a moving train loading. The proposed train-track-bridge model can take into consideration details of track structures, including the distributed rail fasteners, the discontinuous slabs of finite length, and the resilient layer under the slab. Moreover, due 
to the periodic nature of the model, the rail is continuous (i.e., of infinite length) while the discontinuous nature of the slab and the girder are still kept. Such a treatment can help avoiding truncating boundaries that have to be introduced to keep structural components finite in time-domain solution techniques (e.g., finite element modeling or mode superposition method), which would introduce certain arbitrariness into the analysis.

Based on the proposed train-track-bridge interaction model, dynamic responses of the track and the bridge structures are obtained and compared between three different types of tracks, i.e., the double-block ballastless track, the rubber floating slab track, and the steel-spring floating slab track. The rest of the present paper is organized as follows: the train-track-bridge interaction model is introduced, solved, and verified in Sections 2, 3, and 4, respectively; Section 5 describes the engineering background and determines the model parameters; Sections 6 and 7 present the computational results and discussions, and the main findings are concluded in Section 8.

\section{Vertical Train-Track-Bridge Interaction Model}

2.1. Model Descriptions. A two-dimensional model consisting of the train wheels, the beams, and the springs is built for the study of vertical dynamic interactions between the train, the elevated track, and the bridge. As shown in Figure 3, within the bridge span $L$, the model consists of three layers of beams (three-beam unit): the top beam represents the rail; the floating slabs are simulated using discontinuous beams; the bottom layer of beam refers the bridge girder. It is noted that the parallel two rails of the track are integrated into one beam by doubling its bending rigidity and linear mass density, respectively. The distributed springs under each beam (from top to bottom) represent rail fasteners, resilient/damping layer (e.g., rubber layer and steel springs) beneath the slabs, and elastic bearings at girder supports.

It is common in practice for the bridge girder of box section carrying two railway lines, i.e., the up-bound and down-bound tracks. This means neither track is located along the center line of the girder, which would generate torque forces to the bridge girder due to the eccentricity. However, the torsional vibration and its possible coupling with vertical vibration of the bridge girder are not considered herein since the focus of the present study is dynamic responses of different types of railway tracks. The above simplifications, i.e., modeling rail, slab, and girder as single beams, are commonly found in the literature [20-22] in the study of structural and environmental vibrations.

The train vehicle consists of car bodies, bogies, wheels, and suspension systems connecting them. Discrete rigid multibody system of different degrees of freedom (DOFs) has been taken for the modeling of train in the literature $[20,23]$. However, in the present study, the train is modeled as moving sprung wheel mass (as shown in Figure 3), i.e., the car body, the bogie, and the suspension system are not included. This simplification is justified because we limit our attentions to track dynamics, and the moving wheel model is accurate enough for generating wheel/rail forces.

The bending rigidity, linear mass density, and hysteretic damping ratio of the beams are denoted as EI, $m$, and $\eta$ with subscripts "r," "s," and "b" attributing parameters to the rail, the slab, and the girder, respectively. There are $n_{\mathrm{s}}$ slabs of equal length $l_{\mathrm{s}}$ within the girder span length $L$. The stiffness, spacing, and hysteretic damping ratio of the springs are $k, d$, and $\eta$ with subscripts "rp," "sp," and "bp" denoting parameters of the rail fastener, the resilient/damping layer and the elastic bearing, respectively. Specially, $d_{\mathrm{bp}}$ denotes the distance between the elastic bearing and the nearest girder end in the longitudinal direction. The numbers of springs above and beneath a single slab are $n_{\mathrm{rp}}$ and $n_{\mathrm{sp}}$, respectively. There are two elastic bearings under each girder. The equations $L=n_{\mathrm{s}} l_{\mathrm{s}}$ and $l_{\mathrm{s}}=n_{\mathrm{rp}} d_{\mathrm{rp}}=n_{\mathrm{sp}} d_{\mathrm{sp}}$ should be satisfied when setting the parameter values since the gap between neighboring spans is not considered. The mass, the axle load, and the moving velocity of the sprung wheel mass are denoted as $m_{\mathrm{w}}, W$, and $c$, respectively. The stiffness of the contact spring and the interaction force between the wheel and the rail are represented by $k_{\mathrm{H}}$ and $P(t)$, respectively.

2.2. Specific Considerations for Different Tracks. The traintrack-bridge model shown in Figure 3 can be readily adopted for the study of vertical responses of both the rubber-pad and the steel-spring floating slab tracks, i.e., the rubber pad and the steel spring are represented by the distributed springs under the slabs. The resilient and damping features of either the rubber pad or the steel spring can be well captured by setting stiffness and hysteretic damping ratio to the distributed springs of the model.

However, for modeling the double-block ballastless track shown in Figure 1, the discontinuous slab beams and their underlying springs are not included (i.e., only two layers of beams, respectively, representing the rail and the girder, are remained) since the concrete slabs together with the doubleblock sleepers are cast to the bridge girder. Alternatively, the bending rigidity and mass of the concrete slab and the block sleepers are integrated into the girder beam. Such a treatment can also be found in studies by Ju and Lin [20] and Takemiya and Bian [21].

\section{Model Solutions}

3.1. Rail Receptance under a Moving Harmonic Point Load. Firstly, the receptance matrix of the girder beam $\widetilde{R}_{\mathrm{b}}(\omega)$ and the floating slabs $\widetilde{R}_{s}(\omega)$ are obtained by the wave approach [3]. The superscript " $\sim$ " denotes variables in frequency domain, and $\omega$ is the radial frequency. The above receptance matrices are formed at locations of under-slab springs and under-rail springs within the three-beam unit (see Figure 3), respectively. Thus, they are of square matrix of dimension $n_{\mathrm{s}} n_{\mathrm{sp}}$ and $n_{\mathrm{s}} n_{\mathrm{rp}}$, respectively.

By repeating itself along the longitudinal direction (the $x$ axle), the three-beam unit in Figure 3 can form infinite spans of girders carrying a slab track of infinite length. Then, the vertical dynamic response of the infinite rail, subjected to a 


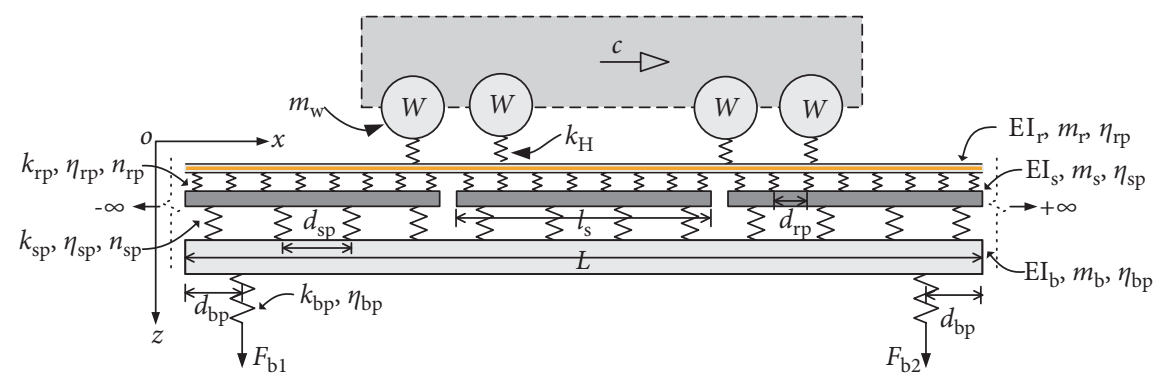

FIGURE 3: Train-track-bridge vertical dynamic interaction model.

moving harmonic point load of magnitude $F_{0}$, oscillating frequency $\omega_{0}$, and moving velocity $c$, can be solved utilizing periodic property of the track. The rail displacement $u_{\mathrm{r}}\left(x^{\prime}, t\right)$ and the reaction force vector $\mathbf{F}_{\mathrm{r}}^{0}(t)$ of the rail fasteners within the $0^{\text {th }}$ three-beam unit can be evaluated as

$$
\begin{aligned}
u_{\mathrm{r}}\left(x^{\prime}, t\right)= & \left(Q_{\mathrm{e}}\left(x^{\prime}\right)+\sum_{m=-\infty}^{+\infty}\left\{\alpha\left(x^{\prime}\right)\right\}_{m} e^{-i 2 \pi m\left(x^{\prime}+x_{0}+c t\right) / L}\right) F_{0} e^{i \omega_{0} t} \\
\mathbf{F}_{\mathrm{r}}^{0}(t)= & \left(-\frac{1}{2 \pi} \int_{-\infty}^{+\infty} D^{-1}\left(\beta_{x}, \omega\right)\left[\mathbf{A}^{-1}\left(\beta_{x}\right)\right]\right. \\
& \left.\cdot\left\{\chi\left(\beta_{x}\right)\right\} e^{-i \beta_{x}\left(x_{0}+c t\right)} d \beta_{x}\right) F_{0} e^{i \omega_{0} t}
\end{aligned}
$$

where

$$
\begin{aligned}
Q_{\mathrm{e}}\left(x^{\prime}\right)= & \frac{1}{2 \pi} \int_{-\infty}^{+\infty} D^{-1}\left(\beta_{x}, \omega\right) e^{i \beta_{x} x^{\prime}} d \beta_{x}, \\
\left\{\alpha\left(x^{\prime}\right)\right\}_{m}= & -\frac{1}{2 \pi L} \int_{-\infty}^{+\infty} D^{-1}\left(\beta_{m}, \omega\right)\left\{\chi^{-1}\left(\beta_{m}\right)\right\}^{T} \\
& \cdot\left[\mathbf{A}\left(\beta_{x}\right)\right]^{-1}\left\{\boldsymbol{X}\left(\beta_{x}\right)\right\} D^{-1}\left(\beta_{x}, \omega\right) e^{i \beta_{x} x^{\prime}} d \beta_{x}, \\
\mathbf{A}(\omega)= & \frac{1}{k_{\mathrm{r}}\left(1+\eta_{\mathrm{r}}\right)} \mathbf{I}+\widetilde{R}_{\mathrm{s}}(\omega)+\frac{1}{L} \sum_{m=-\infty}^{+\infty} D^{-1}\left(\beta_{m}, \omega\right) \Lambda\left(\beta_{m}\right),
\end{aligned}
$$

in which, $\mathbf{I}$ is a unit square matrix of dimension $n_{\mathrm{s}} n_{\mathrm{rp}} ; \boldsymbol{\chi}(\cdot)$ is a vector with dimension $n_{\mathrm{s}} n_{\mathrm{rp}}$; and $\boldsymbol{\Lambda}(\cdot)$ is a square matrix with dimension $n_{\mathrm{s}} n_{\mathrm{rp}}$. Their elements are given as

$$
\left\{\begin{array}{l}
(\boldsymbol{\chi})_{i}=e^{i \beta_{x} x_{\mathrm{r} i}}, \\
(\boldsymbol{\Lambda})_{i, j}=e^{-i \beta_{m}\left(x_{\mathrm{r} j}-x_{\mathrm{ri}}\right)}, \\
i, j=1,2, \ldots, n_{\mathrm{s}} n_{\mathrm{rp}},
\end{array}\right.
$$

$x_{\mathrm{ri}}$ denotes coordinate of the $i^{\text {th }}$ under-rail spring within the $0^{\text {th }}$ three-beam unit; $x^{\prime}=x-x_{0}-c t$ is the observation axle moving along with the point load; $x_{0}$ is the initial position of the load; $\beta_{x}$ is the wavenumber, it is related to $\omega$ through $\omega=\omega_{0}-\beta_{x} c ; \quad \beta_{m}=\beta_{x}-2 \pi m / L ; \quad D\left(\beta_{x}, \omega\right)=\mathrm{EI}_{\mathrm{r}}\left(1+\eta_{\mathrm{r}}\right)$ $\beta_{x}^{4}-\omega^{2} m_{\mathrm{r}}$. For the details of the derivations, one is referred to paper [3] by the corresponding author.
3.2. Solution of Wheel/Rail Interaction. Sheng et al. [24] developed a Fourier series-based approach for the study of dynamic interactions between the moving sprung wheel mass and an infinite rail periodically supported by sleepers (i.e., the period is the sleeper spacing). The approach can be applied directly to the problem at hand after changing the period to the girder length $L$. The solution procedure of the wheel/rail interaction problem is generally the same as that mentioned by Sheng et al. [24] and is briefly listed below.

The vertical displacement $u_{\mathrm{w}}$ (directed upwards) of the rigid wheel mass is governed by

$$
m_{\mathrm{w}} \ddot{u}_{\mathrm{w}}(t)=P(t)-W
$$

where the dot over the variable denotes differential over time. The compressive wheel/rail force $P(t)$ can be expressed as follows, using the Fourier series.

$$
P(t)=\sum_{k=-\infty}^{k=+\infty} \widetilde{P}_{k} e^{i k \Omega_{0} t}
$$

where $\Omega_{0}=2 \pi c / L$ and the component corresponding to zero frequency $(k=0)$ is the static load, i.e., $\widetilde{P}_{0}=W$. Similarly, the vertical wheel displacement is expressed as

$$
u_{\mathrm{w}}(t)=\sum_{k=-\infty}^{k=+\infty} g_{k} \widetilde{P}_{k} e^{i k \Omega_{0} t}
$$

where $g_{k}$ is the direct receptance of the wheel at frequency $k \Omega_{0}$. From equation (5), $g_{k}$ can be determined as

$$
g_{k}= \begin{cases}\text { to be defined, } & k=0, \\ -\frac{1}{m_{\mathrm{w}}\left(k \Omega_{0}\right)^{2}}, & k \neq 0 .\end{cases}
$$

Based on equation (1), the rail displacement (directed downwards) at the contact point due to the moving wheel/ rail force can be given as

$$
u_{\mathrm{r}}(t)=\sum_{k=-\infty}^{+\infty} \widetilde{P}_{k}\left(\sum_{m=-\infty}^{+\infty} r_{m}\left(k \Omega_{0}\right) e^{-i m \Omega_{0} t}\right) e^{i k \Omega_{0} t}
$$

where $r_{m}\left(k \Omega_{0}\right)$ is the $(-m)^{\text {th }}$ Fourier coefficient of the rail displacement amplitude (i.e., the bracketed term on right side of equation (1)) that is generated by a moving point load $\widetilde{P}_{k}$ of oscillating frequency $k \Omega_{0}$, i.e., 


$$
r_{m}\left(k \Omega_{0}\right)= \begin{cases}\left\{\alpha\left(x^{\prime}\right)\right\}_{m} e^{-i 2 \pi m\left(x^{\prime}+x_{0}\right) / L}, & m \neq 0, \\ Q_{e}\left(x^{\prime}\right)+\left\{\alpha\left(x^{\prime}\right)\right\}_{0}, & m=0 .\end{cases}
$$

Equation (9) can be further manipulated as

$$
u_{\mathrm{r}}(t)=\sum_{k=-\infty}^{k=+\infty}\left(\sum_{m=-\infty}^{m=+\infty} r_{m-k}\left(m \Omega_{0}\right) \widetilde{P}_{m}\right) e^{i k \Omega_{0} t}
$$

The wheel is assumed to be always in contact with the rail via a linearized Hertz contact spring $\left(k_{\mathrm{H}}\right)$, which requires

$$
u_{\mathrm{w}}(t)+u_{\mathrm{r}}\left(x_{0}+c t, t\right)+\delta_{0}+\frac{(P(t)-W)}{k_{\mathrm{H}}}=z\left(x_{0}+c t\right),
$$

where $\delta_{0}$ is the static deformation of the contact spring under the static load $W ; z(x)=A \cos (2 \pi x / \lambda)$ is a sine irregularity at rail head, where $A$ is the amplitude and $\lambda$ is the wavelength. The sine irregularity of wavelength $\lambda$ may break the periodicity formed by repetition of the threebeam unit of length $L$ if $L / \lambda$ is not an integer. To simplify the analysis, the value of $\lambda$ is set so that $L / \lambda=k$ and $k$ is an integer. This simplification does not limit the applicability of the present model. For example, for a bridge girder of length $L=30 \mathrm{~m}$, the wavelength of rail irregularity can be $5 \mathrm{~m}, 3 \mathrm{~m}, 1 \mathrm{~m}, 0.5 \mathrm{~m}$, etc., which falls in the possible range of irregularity wavelength from in-situ measurement. The sine irregularity $z(x)$ can be further expressed in the exponential form, i.e.,

$$
z(x)=\frac{1}{2} A e^{i k \beta_{0} x}+\frac{1}{2} A e^{-i k \beta_{0} x},
$$

where $\beta_{0}=2 \pi / L$. Inserting equations (6), (7), (11), and (13) into equation (12) yields

$$
\begin{gathered}
\left(g_{k}+\frac{1}{k_{\mathrm{H}}}\right) \widetilde{P}_{k}+\sum_{m=-\infty, m \neq 0}^{\infty} r_{m-k}\left(m \Omega_{0}\right) \widetilde{P}_{m} \\
=\widetilde{Z}_{k} e^{i k \beta_{0} x_{0}}-r_{-k}\left(0 \Omega_{0}\right) W, \quad k \neq 0, \\
g_{0} W+\sum_{m=-\infty}^{\infty} r_{m}\left(m \Omega_{0}\right) \widetilde{P}_{m}=-\delta_{0}, \quad k=0 .
\end{gathered}
$$

From equation (14), the amplitude $\widetilde{P}_{k}(k= \pm 1, \pm 2, \ldots)$ of the harmonic components of the wheel/rail force can be determined. From equation (15), the wheel receptance $g_{0}$ corresponding to zero frequency (see equation (8)) can be obtained. The wheel/rail force at any time $t$ can be synthesized from these harmonic components through equation (6). Then, the wheel and rail displacements at the contact point can be obtained by back substituting $\widetilde{P}_{k}(k=0, \pm 1, \pm 2, \ldots)$ into equations (7) and (11), respectively. Similarly, substituting $\widetilde{P}_{k}$ into equation (2), the reaction forces at rail fasteners can be determined after synthetization with respect to $k$. Finally, the displacement and the forces of underlying springs associating with the slabs as well as the girder can be calculated by back substitution reaction forces of the rail fasteners into the slab and girder receptance matrix, respectively.

\section{Model Verification}

Sheng et al. [24] have solved the problem of dynamic interactions between the moving sprung wheel mass and the conventional ballast track. In their model, the track is composed of an infinite rail beam, equally spaced rigid sleepers, springs above the sleepers representing rail pads and springs under the sleepers representing the ballast. The bottom of the ballast spring is fixed (i.e., the ballast is on rigid ground). In order to compare with the published results, our model presented in Figure 3 is reduced by setting large bending rigidity to the girder beam and the slab beam and setting large stiffness to the girder supports, so that the rigid ground and rigid sleeper can be simulated. Meanwhile, the mass and length of the slab beam are set to values of the sleeper. The wheel/rail forces are obtained and compared with their results for a single wheel moving along with a smooth railhead (i.e., $A=0$ ). Parameters of the wheel, the rail, the sleeper, and the springs connecting them are taken from their paper and listed in Table 1.

Comparison results on the spectrum and time-history of wheel/rail force are presented in Figures 4(a) and 4(b), respectively. It is observed that the computational results agree well with the published data, which verifies the correctness of the present model.

\section{Engineering Background and Model Parameters}

A line of URT is elevated using bridges on pile foundations at a coastal city of south China since the place is deposited of mega-thick slurry soil (thickness can reach $50 \mathrm{~m}$ ), and it is generally difficult to construct metro tunnels in such a weak ground condition. One section of the URT runs closely to an existing vibration-sensitive facility. Concerns arise on excess vibration of the facility induced by the URT train running at a maximum speed of $120 \mathrm{~km} / \mathrm{h}$.

The URT adopts a double-block ballastless track in an original design. According to the design documents, it consists of the U75V new rail, the WJ-7B rail fastener and the SK-1 double-block sleepers. The concrete slab (see Figure 1) of length $5 \sim 7 \mathrm{~m}$ and width $2.8 \mathrm{~m}$ is cast in place to the bridge girder. In order to control vibrations at source, two alternative types of tracks, i.e., the rubber-pad floating slab track and the steel-spring floating slab track, have been proposed.

5.1. Model Parameter of Railway Track. Track components of the rubber-pad floating slab track are the same as those of the double-block ballastless track, except that the concrete slab of length $5 \sim 7 \mathrm{~m}$ and width $3 \mathrm{~m}$ is supported by the rubber pad. The rubber pad's thickness is $27 \mathrm{~mm}$ and its designed static stiffness is $0.025 \mathrm{~N} / \mathrm{mm}^{3}$.

Components of the floating slab track designed as the heavier rail (of linear mass density $60.64 \mathrm{~kg} / \mathrm{m}$ ), the DTV-I2 rail fastener, the SK-1 double-block sleeper, the concrete slab of length $7 \mathrm{~m}$ and width $3.51 \mathrm{~m}$ and the under-slab steel springs. Design value of spring spacing along the 
TABle 1: Parameters of train wheel and conventional ballast track from Sheng et al. [24].

\begin{tabular}{lcc}
\hline Parameter & Symbol & Value \\
\hline Wheel mass & $m_{\mathrm{w}}$ & $1350 \mathrm{~kg}$ \\
Axle load & $W$ & $100 \mathrm{kN}$ \\
Wheel moving velocity & $c$ & $40 \mathrm{~m} / \mathrm{s}$ \\
Wheel/rail spring stiffness & $k_{\mathrm{H}}$ & $1.40 \times 10^{9} \mathrm{~N} / \mathrm{m}$ \\
Beading rigidity of rail & $\mathrm{EI}_{\mathrm{r}}$ & $6.42 \times 10^{6} \mathrm{~N} \cdot \mathrm{m}^{2}$ \\
Linear mass density of rail & $m_{\mathrm{r}}$ & $120.73 \mathrm{~kg} / \mathrm{m}$ \\
Hysteretic damping ratio of rail & $\eta_{\mathrm{r}}$ & 0.01 \\
Stiffness of rail fastener & $k_{\mathrm{rp}}$ & $3.50 \times 10^{8} \mathrm{~N} / \mathrm{m}$ \\
Hysteretic damping ratio of rail fastener & $\eta_{\mathrm{rp}}$ & 0.25 \\
Spacing of rail fasteners & $d_{\mathrm{rp}}$ & $0.6 \mathrm{~m}$ \\
Linear mass density of slab & $m_{\mathrm{s}}$ & $648 \mathrm{~kg} / \mathrm{m}$ \\
Length of slab & $l_{\mathrm{s}}$ & $0.25 \mathrm{~m}$ \\
Stiffness of under-slab spring & $k_{\mathrm{sp}}$ & $5.0 \times 10^{7} \mathrm{~N} / \mathrm{m}$ \\
Hysteretic damping ratio of under-slab spring & $\eta_{\mathrm{sp}}$ & 1.0 \\
Spacing of under-slab spring & $d_{\mathrm{sp}}$ & $0.6 \mathrm{~m}$ \\
\hline
\end{tabular}

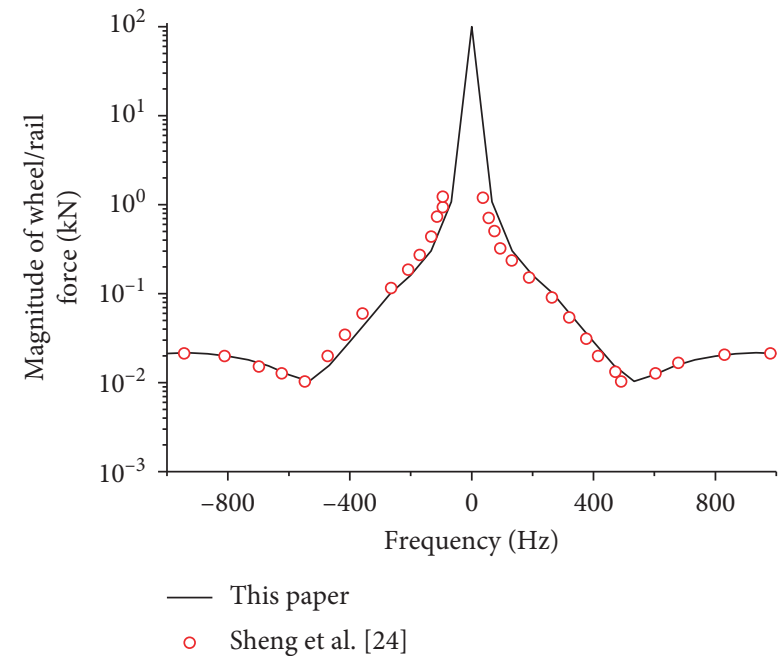

(a)

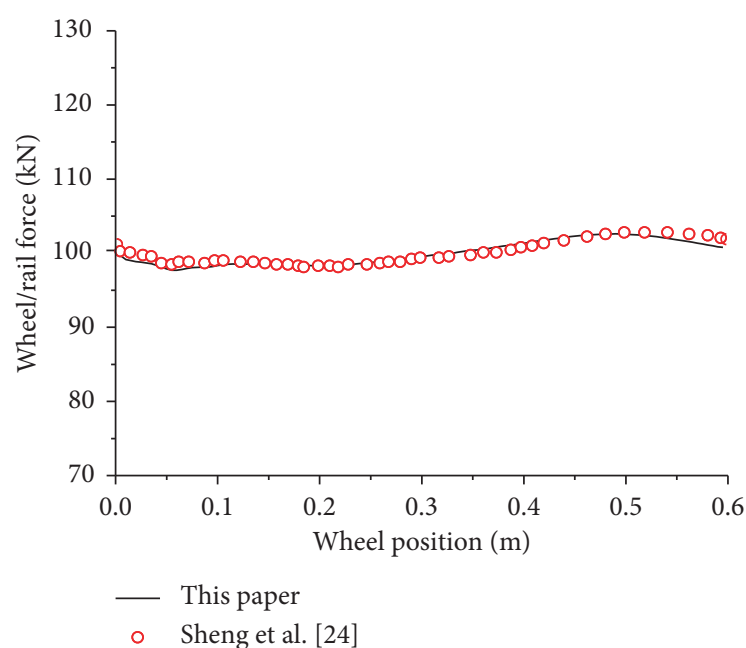

(b)

Figure 4: Comparison on wheel/rail forces between the present paper and published data: (a) spectrum; (b) position history.

longitudinal direction is $1.25 \mathrm{~m}$. And the total dynamic stiffness of the steel spring summed over the traverse direction is set to $30 \mathrm{MN} / \mathrm{m}$. Parameters of the rubber-pad floating slab track and of the steel-spring floating slab tracks are taken from the design documents and listed in Tables 2 and 3 , respectively.

To avoid repetition, parameters of the double-block ballastless track are not listed, because they can be obtained by reducing the rubber-pad floating slab track after neglecting the springs under the slab and integrating the mass and stiffness of the slab into the bridge girder, as depicted in Section 2.2.

It is noted that the linear mass density of the slab associating with the steel-spring floating slab track is much higher than that of the rubber-pad floating slab track. However, the stiffness of steel spring is lower than that of the rubber layer. As a result, for the steel-spring floating slab track, a lower resonance frequency of the floating slab can be achieved, which would be beneficial in controlling environmental vibrations.

\subsection{Model Parameters of Train Wheel/Rail Interaction.}

The URT train has 4 carriages and 16 wheels in total (i.e., 4 wheels for each carriage). The distance between the wheels and the axle load applied is schematically shown in Figure 5. According to Criteria EN13231-3: 2006 for acceptable rail grinding, the limit for peak-to-peak amplitude of rail irregularity in the $0.3 \sim 1 \mathrm{~m}$ wavelength range is $100 \mu \mathrm{m}$ [25]. Thus, a sine irregularity of amplitude $A=50 \mu \mathrm{m}$ and wavelength $\lambda=0.552 \mathrm{~m}$ is assigned to the rail irregularity profile. Table 4 summarizes values of parameters associating with the train wheel and the rail irregularity.

5.3. Model Parameter of Bridge Girder. As mentioned above, the URT line is elevated when it passes area of the vibration- 
TABLE 2: Model parameters of rubber-pad floating slab track.

\begin{tabular}{lcc}
\hline Parameter & Symbol & Value \\
\hline Rail bending stiffness & $\mathrm{EI}_{\mathrm{r}}$ & $1.3247 \times 10^{7} \mathrm{~N} \cdot \mathrm{m}^{2}$ \\
Rail linear mass & $m_{\mathrm{r}}$ & $120 \mathrm{~kg} / \mathrm{m}$ \\
Hysteretic damping ratio of rail & $\eta_{\mathrm{r}}$ & 0.001 \\
Under-rail spring stiffness & $k_{\mathrm{rp}}$ & $9.0 \times 10^{7} \mathrm{~N} / \mathrm{m}$ \\
Hysteretic damping ratio of under-rail spring & $\eta_{\mathrm{rp}}$ & 0.2 \\
Number of springs above one slab & $n_{\mathrm{rp}}$ & 10 \\
Under-rail spring spacing & $d_{\mathrm{rp}}$ & $0.58 \mathrm{~m}$ \\
Slab bending stiffness & $\mathrm{EI}_{\mathrm{s}}$ & $2.34 \times 10^{8} \mathrm{~N} \cdot \mathrm{m}^{2}$ \\
Slab linear mass & $m_{\mathrm{s}}$ & $2323.2 \mathrm{~kg} / \mathrm{m}$ \\
Hysteretic damping ratio of slab & $\eta_{\mathrm{s}}$ & 0.05 \\
Number of slabs in one unit & $n_{\mathrm{s}}$ & 6 \\
Number of springs beneath one slab & $n_{\mathrm{sp}}$ & 4 \\
Slab length & $l_{\mathrm{s}}$ & $5.8 \mathrm{~m}$ \\
Under-slab spring stiffness & $k_{\mathrm{sp}}$ & $1.74 \times 10^{8} \mathrm{~N} / \mathrm{m}$ \\
Hysteretic damping ratio of under-slab spring & $\eta_{\mathrm{sp}}$ & 0.25 \\
Under-slab spring spacing & $d_{\mathrm{sp}}$ & $1.45 \mathrm{~m}$ \\
\hline
\end{tabular}

TABLE 3: Model parameters of steel-spring floating slab track.

\begin{tabular}{lcc}
\hline Parameter & Symbol & Value \\
\hline Rail bending stiffness & $\mathrm{EI}_{\mathrm{r}}$ & $1.3453 \times 10^{7} \mathrm{~N} \cdot \mathrm{m}^{2}$ \\
Rail linear mass & $m_{\mathrm{r}}$ & $121.28 \mathrm{~kg} / \mathrm{m}$ \\
Hysteretic damping ratio of rail & $\eta_{\mathrm{r}}$ & 0.001 \\
Under-rail spring stiffness & $k_{\mathrm{rp}}$ & $8.7 \times 10^{7} \mathrm{~N} / \mathrm{m}$ \\
Hysteretic damping ratio of under-rail spring & $\eta_{\mathrm{rp}}$ & 0.2 \\
Number of springs above one slab & $n_{\mathrm{rp}}$ & 8 \\
Under-rail spring spacing & $d_{\mathrm{rp}}$ & $0.625 \mathrm{~m}$ \\
Slab bending stiffness & $\mathrm{EI}_{\mathrm{s}}$ & $2.39 \times 10^{8} \mathrm{~N} \cdot \mathrm{m}^{2}$ \\
Slab linear mass & $m_{\mathrm{s}}$ & $3085.3 \mathrm{~kg} / \mathrm{m}$ \\
Hysteretic damping ratio of slab & $\eta_{\mathrm{s}}$ & 0.05 \\
Number of slabs in one unit & $n_{\mathrm{s}}$ & 7 \\
Number of springs beneath one slab & $n_{\mathrm{sp}}$ & 4 \\
Slab length & $l_{\mathrm{s}}$ & $5.0 \mathrm{~m}$ \\
Under-slab spring stiffness & $k_{\mathrm{sp}}$ & $3 \times 10^{7} \mathrm{~N} / \mathrm{m}$ \\
Hysteretic damping ratio of under-slab spring & $\eta_{\mathrm{sp}}$ & 0.25 \\
Under-slab spring spacing & $d_{\mathrm{sp}}$ & $1.25 \mathrm{~m}$ \\
\hline
\end{tabular}

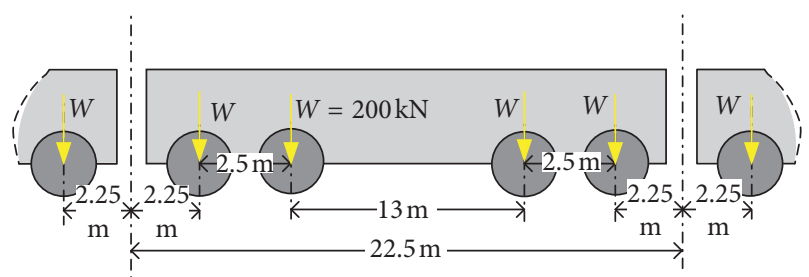

FIgURE 5: Distance and axle load of train wheels within one carriage.

TABLE 4: Modal parameters of train wheel and rail irregularity.

\begin{tabular}{lcc}
\hline Parameter & Symbol & Value \\
\hline Wheel mass & $m_{\mathrm{w}}$ & $1350 \mathrm{~kg}$ \\
Axle load & $W$ & $200 \mathrm{kN}$ \\
Wheel/rail contact stiffness & $k_{\mathrm{H}}$ & $2.8 \times 10^{9} \mathrm{~N} / \mathrm{m}$ \\
Train velocity & $c$ & $120 \mathrm{~km} / \mathrm{h}$ \\
Rail irregularity wavelength & $\lambda$ & $0.552 \mathrm{~m}$ \\
Rail irregularity amplitude & $A$ & $50 \mu \mathrm{m}$ \\
\hline
\end{tabular}

sensitive facility. According to the design documents, a simply supported girder of box section carrying two track lines has been used. The girder of span length $34.8 \mathrm{~m}$ is cast in place using C50 concrete. At girder supports, steel supports specially designed for rail transit have been adopted. Parameters of the bridge girder are given in Table 5 .

\section{Dynamic Responses of Train-Track- Bridge System}

With the inputs of the above model parameters, dynamic responses of the wheel/rail interaction, the track and the bridge girder can be evaluated and compared for the three types of tracks, i.e., the double-block ballastless track (DBB track), the rubber-pad floating slab track (RPFS track), and the steel-spring floating slab track (SSFS track), by following the solution procedure depicted in Section 3.

6.1. Dynamic Wheel/Rail Forces. The spectrum and timehistory of the wheel/rail forces are presented in Figures 6 
TABLE 5: Model parameters of bridge girder.

\begin{tabular}{lcc}
\hline Parameter & Symbol & Value \\
\hline Girder bending stiffness & $\mathrm{EI}_{\mathrm{b}}$ & $1.533 \times 10^{11} \mathrm{~N} \cdot \mathrm{m}^{2}$ \\
Girder linear mass & $m_{\mathrm{b}}$ & $2.0163 \times 10^{4} \mathrm{~kg} / \mathrm{m}$ \\
Hysteretic damping ratio of girder & $\eta_{\mathrm{b}}$ & 0.05 \\
Under-girder spring stiffness & $k_{\mathrm{bp}}$ & $1.0 \times 10^{13} \mathrm{~N} / \mathrm{m}$ \\
Hysteretic damping ratio of under-girder spring & $\eta_{\mathrm{bp}}$ & 0.01 \\
Under-girder spring spacing & $d_{\mathrm{bp}}$ & $0.65 \mathrm{~m}$ \\
Girder span length & $L$ & $34.8 \mathrm{~m}$ \\
\hline
\end{tabular}

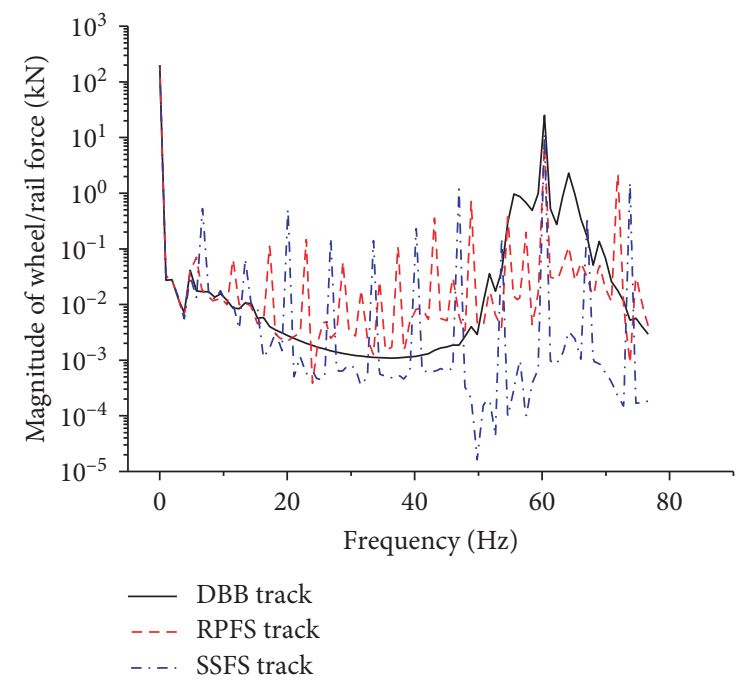

FIgURE 6: Spectrum of wheel/rail forces at the first wheel.

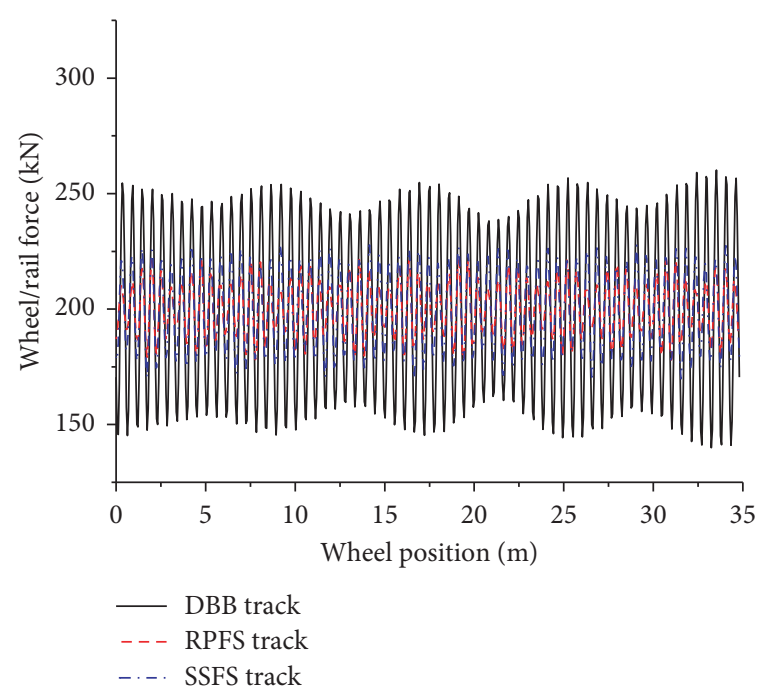

Figure 7: Time history of wheel/rail forces at the first wheel.

and 7, respectively. Only responses of the first wheel (out of 16 wheels in total) are given here, the others generally give similar results. From Section 3, it is clear that the wheel/rail force is a periodic function with respect to coordinate $x$, and the periodicity is the girder span length $L$. Thus, in Figure 7, the time history is plotted against position of the wheel within a single girder span.
From Figure 6, it is seen that three are two peaks in wheel/rail force spectrum of the DBB track, i.e., one is the axle load $(200 \mathrm{kN})$ at 0 frequency, and the other is a board peak around the rail roughness excitation frequency $(=c / \lambda=60.34 \mathrm{~Hz})$. The two peaks above can also be observed for the RPFS track and the SSFS track. The three types of tracks have the same peak value at 0 frequency. However, peak values at the roughness excitation frequency are $25.06 \mathrm{kN}, 7.56 \mathrm{kN}$, and $11.81 \mathrm{kN}$ for the DBB, RPFS, and SSFS tracks, respectively, accounting for $12.5 \%, 3.8 \%$, and $5.9 \%$ of the axle load. Besides the two peaks discussed above, peaks of smaller values also exist for the RPFS and SSFS tracks. Those peaks correspond to the slab passing frequency $\left(=c / l_{\mathrm{s}}\right)$ and its multipliers. As a result, the peak spacing is $c / l_{\mathrm{s}}=33.3 / 5.8=5.7 \mathrm{~Hz}$ and $c / l_{\mathrm{s}}=33.3 / 5.0=6.7 \mathrm{~Hz}$, respectively, for the RPFS track and the SSFS track. Since the slabs are not explicitly considered in the DBB track model, there are no peaks that are rendered by the wheel periodically passing the slab in its wheel/rail force spectrum.

From the time histories for different tracks, it is seen that the DBB track has the largest wheel/rail force $(260.2 \mathrm{kN}$ to the maximum), which is $17.2 \%$ and $14.2 \%$ larger than that of the RPFS track and the SSFS track, respectively.

6.2. Dynamic Track Responses. Similarly, displacement of the rail at the wheel/rail contact point is periodic, and its time history is plotted in Figure 8. It is seen that the rail displacement generally reaches a maximum when the wheel moves towards the midspan; then it drops when the wheel approaches the end-span. It is clear that the SSFS track has the largest rail displacement (5.8 $\mathrm{mm}$ to the maximum); and the rail displacement of the RPFS track $(3.58 \mathrm{~mm}$ to the maximum) is slightly larger than that of the DBB track (maximum is $3.43 \mathrm{~mm}$ ). Since the steel-spring is softer than the rubber pad, it is within expectation that the rail displacement of the SSFS track can be $60 \%$ larger than that of the RPFS or DBB track. The Technical Code for Floating Slab Track at China requires that the maximum vertical rail displacement should not be larger than $4 \mathrm{~mm}$ when the rated train load is applied. It is seen from Figure 8 that the rail displacement of the SSFS track may easily exceed this limit when the wheel passes the observation point at the midspan of the bridge. However, when the wheel is close to two supports at two ends of the bridge girder, the rail displacement is less than $4 \mathrm{~mm}$. In view of the above, the SSFS track is not suggested for the elevated railway line.

Figure 9 presents time histories of reaction forces of the rail fasteners for all four carriages passing the bridge span. It 


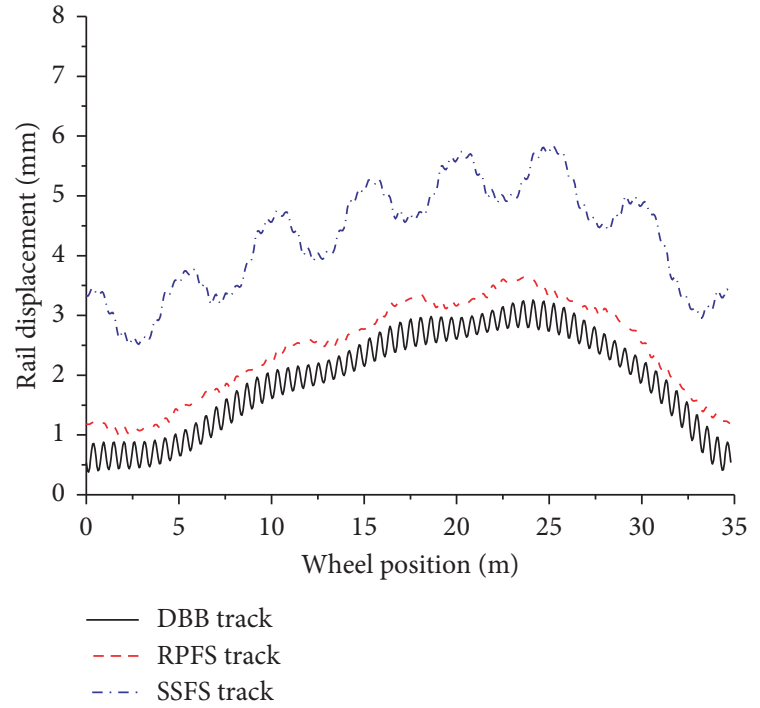

Figure 8: Time history of rail displacement at wheel/rail contact point.

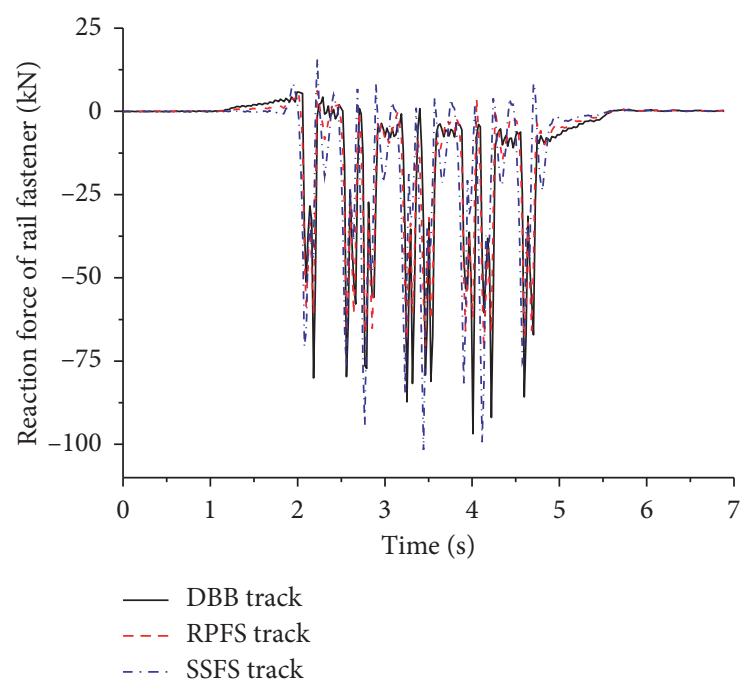

Figure 9: Time histories of reaction force of rail fastener.

is seen that uplift force develops in the rail fasteners before the arriving of the train wheels, however, with limited amplitude around $6 \sim 8 \mathrm{kN}$, for all three types of tracks. For the DBB and RBFS tracks, their rail fasteners experience compressive force immediately after the arriving of the $1^{\text {st }}$ wheel. However, significant uplift force that reaches a maximum of $15.7 \mathrm{kN}$ develops for the SSFS track. The design documents require that the minimum compressive installation force is $18 \mathrm{kN}$ and $16.5 \mathrm{kN}$, respectively, for WJ-7B fastener (associating with the DBB and RPFS tracks) and DTV-I2 fastener (associating with the SSFS track). Thus, for the SSFS track, the uplift force developed is very close to the installation force of the fastening clip, which may cause failure of its rail fasteners under repetition of train loads.

6.3. Dynamic Girder Responses. The bridge girder is an intermediate part connecting the track that generates vibrations

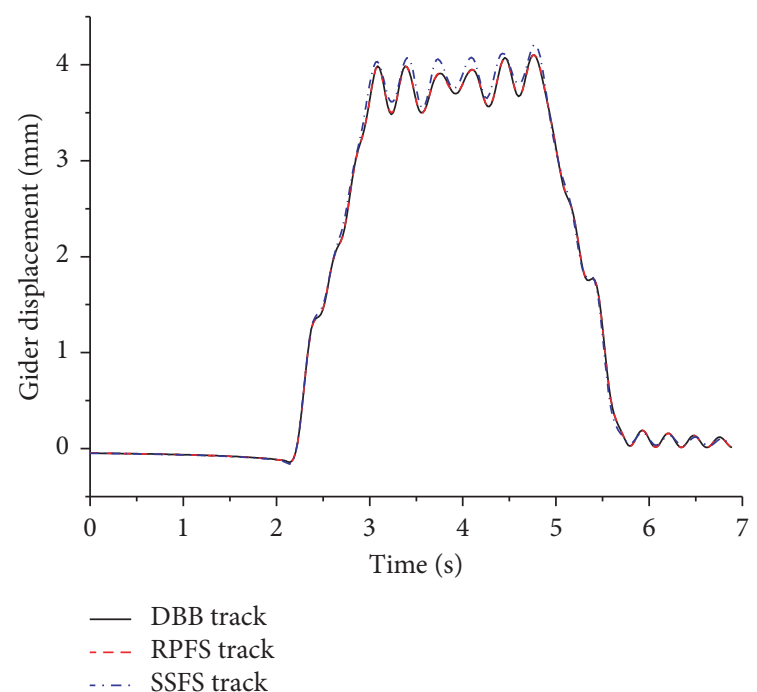

Figure 10: Time history of girder vertical displacement observed at midspan.

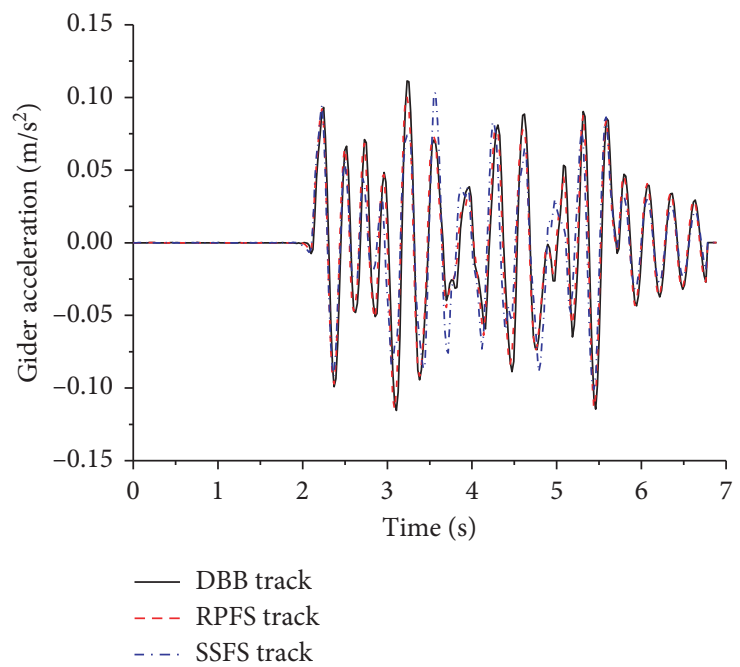

FIgURE 11: Time history of girder vertical acceleration observed at midspan.

with the foundation and then the ground, which is receiver of the transmitted vibrations. Thus, the girder displacement, acceleration response, and resulting reaction forces at the girder supports determine environmental-vibration levels. Time histories of vertical displacement and acceleration response at midspan of the girder are presented in Figures 10 and 11, respectively. Dynamic reaction forces at the two girder supports are plotted in Figure 12.

It is observed from Figures 10 and 11 that girder displacement and acceleration response almost overlap for the DBB track and the RPFS track, while for the SSFS track, its girder displacement is slightly larger and its acceleration is slightly smaller.

For reaction forces at girder supports, results of three tracks share the same tendency when the time evolves. It is observed that reaction forces of both the RPFS (max. $803 \mathrm{kN}$ ) and SSFS (max. $761 \mathrm{kN})$ tracks are smaller than 


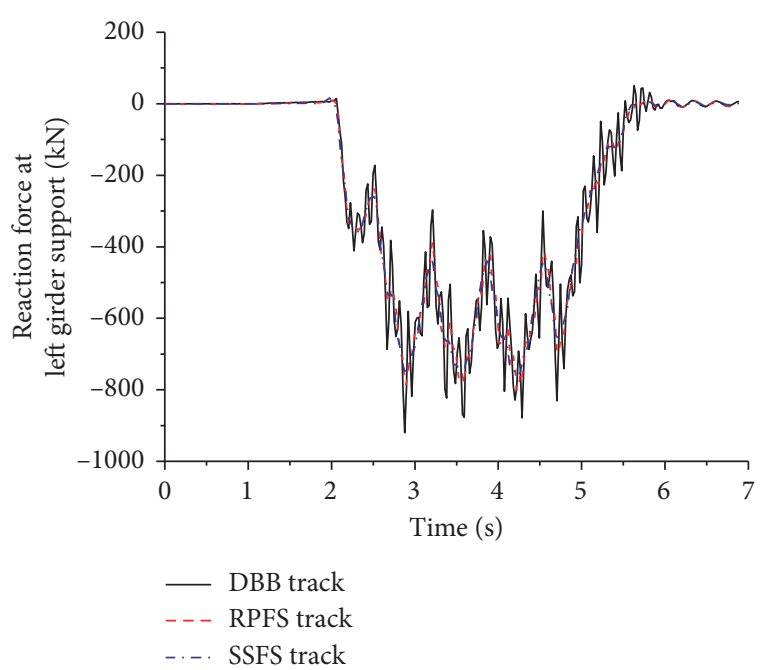

(a)

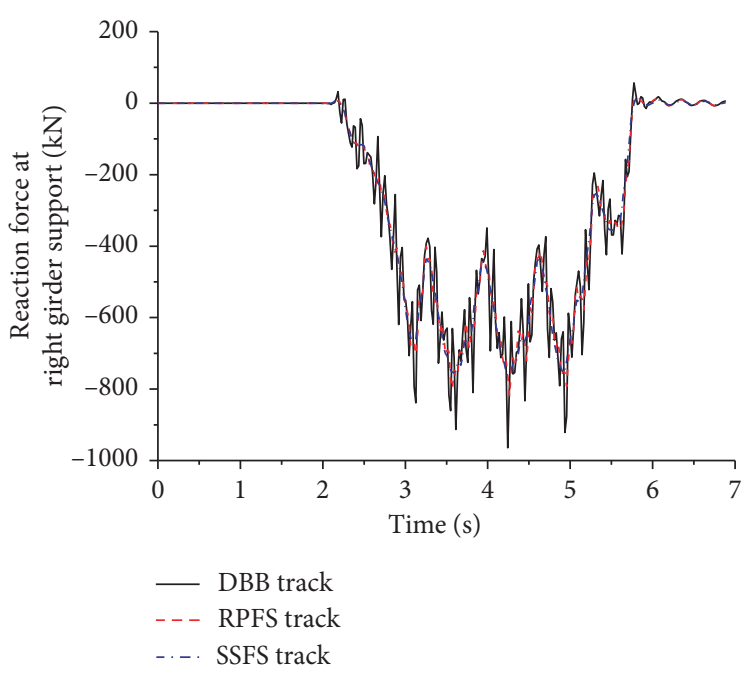

(b)

FIGURE 12: Time history of reaction forces at girder supports: (a) left support; (b) right support.

those of the DBB track (max. $920 \mathrm{kN}$ ) since the screening effect of the floating slab can help attenuating vibrations at frequencies higher than its characteristic resonance frequency [3]. There are about $13 \%$ and $16 \%$ of reduction in loads transferred to pier, respectively, for the RPFS and SSFS tracks, when compared to the conventional DBB track. It is always beneficial to reduce dynamic loads transferred to foundation and ground in viewing of environmental vibration control.

\section{Discussion}

The SSFS track, of heavier slabs floating on resilient layer of lower stiffness, is most effective in reducing dynamic loads at girder supports, which will be transmitted to the pier, the foundation, and then the ground. Thus, the SSFS track would be the most suitable one in viewing of controlling environmental vibrations generated by the elevated railway lines. However, its suitability is limited by large rail deflection that exceeds $4 \mathrm{~mm}$ at midspan of the bridge and by large uplifting force comparable to installing forces of the rail fastener since detrimental outcomes including reduction in riding comfortability and increased risk in rail fastener failure would be expected for this type of track.

On the contrary, the DBB track has the smallest rail deflection. However, its wheel/rail force and reaction force at girder supports are the largest, which may accelerate wheel/ rail corrugations and generate excess environmental vibrations.

Fortunately, the RPFS track comes up with rail deflections comparable to the DBB track and wheel/rail forces and girder support forces comparable to the SSFS track, as well as acceptable uplifting forces of rail fasteners. Thus, the RPFS track provides a more balanced solution in facing the dilemma of maintaining track quality and keeping riding comfortability while reducing environmental vibrations.

\section{Conclusions}

A train-track-bridge vertical interaction model has been established in the present paper to make a comparative study on dynamic responses between three types of tracks, i.e., the double-block ballastless track, the rubber-pad floating slab track, and the steel-spring floating slab track. The model is solved using periodic structure theory, and the solution has been verified by comparing to published data. With the inputs of model parameters determined from design documents of engineering practice, dynamic model outputs including the wheel/ rail forces, the rail/girder deflections, and the reaction forces at rail fasteners and girder supports are obtained and analyzed. Based on the above, the following conclusions can be drawn:

(1) The wheel/rail force of the double-block ballastless track is $17.2 \%$ and $14.2 \%$ larger than that of the rubberpad and steel-spring floating slab tracks, respectively.

(2) The rail displacement of the steel-spring floating slab track can be $60 \%$ larger than that of the rubber-pad floating slab track and the double-block ballastless track.

(3) The steel-spring floating slab track is the only one that develops an uplifting force comparable to installation force of the fastening clip.

(4) There are about $13 \%$ and $16 \%$ of reduction in loads transferred to pier, respectively, for the rubber-pad and steel-spring floating tracks, when compared to the double-block ballastless track.

(5) The rubber-pad floating slab track provides a balanced solution in facing the dilemma of maintaining track quality and keeping riding comfortability while reducing environmental vibrations.

\section{Data Availability}

The data used to support the findings of this study are available from the corresponding author upon request. 


\section{Conflicts of Interest}

The authors declare that there are no conflicts of interest.

\section{Acknowledgments}

Financial supports from the National Natural Science Foundation of China (Grant nos. 51608482 and 51879234) and from the CCCC Highway Consultants Co., Ltd. (Contract nos. Q17529-18-1) are sincerely acknowledged.

\section{References}

[1] L. Guo, J. Chen, J. Wang, Y. Cai, and P. Deng, "Influences of stress magnitude and loading frequency on cyclic behaviour of $K_{0}$-consolidated marine clay involving principal stress rotation," Soil Dynamics and Earthquake Engineering, vol. 84, pp. 94-107, 2016.

[2] L. Shi, H.-L. Sun, X.-D. Pan, X.-Y. Geng, and Y.-Q. Cai, “A theoretical investigation on characteristic frequencies of ground vibrations induced by elevated high speed train," Engineering Geology, vol. 252, pp. 14-26, 2019.

[3] L. Shi, Y. Cai, P. Wang, and H. Sun, "A theoretical investigation on influences of slab tracks on vertical dynamic responses of railway viaducts," Journal of Sound and Vibration, vol. 374, pp. 138-154, 2016.

[4] W. Zhai, K. Wang, and C. Cai, "Fundamentals of vehicle-track coupled dynamics," Vehicle System Dynamics, vol. 47, no. 11, pp. 1349-1376, 2009.

[5] S. Zhu, J. Wang, C. Cai et al., "Development of a vibration attenuation track at low frequencies for urban rail transit," Computer-Aided Civil and Infrastructure Engineering, vol. 32, no. 9, pp. 713-726, 2017.

[6] S. Zhu, J. Yang, C. Cai, Z. Pan, and W. Zhai, "Application of dynamic vibration absorbers in designing a vibration isolation track at low-frequency domain," Proceedings of the Institution of Mechanical Engineers, Part F: Journal of Rail and Rapid Transit, vol. 231, no. 5, pp. 546-557, 2017.

[7] F. Cui and C. H. Chew, "The effectiveness of floating slab track system-part I: receptance methods," Applied Acoustics, vol. 61, no. 4, pp. 441-453, 2000.

[8] G. Lombaert, G. Degrande, B. Vanhauwere, B. Vandeborght, and S. François, "The control of ground-borne vibrations from railway traffic by means of continuous floating slabs," Journal of Sound and Vibration, vol. 297, no. 3-5, pp. 946-961, 2006.

[9] Y. Dere, "Effectiveness of the floating slab track system constructed at Konya Light Rail," Measurement, vol. 89, pp. 48-54, 2016.

[10] M. Ma, W. Liu, C. Qian, G. Deng, and Y. Li, "Study of the train-induced vibration impact on a historic bell tower above two spatially overlapping metro lines," Soil Dynamics and Earthquake Engineering, vol. 81, pp. 58-74, 2016.

[11] T. Xin and L. Gao, "Reducing slab track vibration into bridge using elastic materials in high speed railway," Journal of Sound and Vibration, vol. 330, no. 10, pp. 2237-2248, 2011.

[12] D. P. Connolly, G. P. Marecki, G. Kouroussis, I. Thalassinakis, and P. K. Woodward, "The growth of railway ground vibration problems-a review," Science of the Total Environment, vol. 568, pp. 1276-1282, 2015.

[13] G. S. Jee, H. H. Nguyen, S. Y. Jang, H. Lee, and W. Chung, "Key characteristics of a floating slab track based on longitudinal interaction analysis," Mathematical Problems in Engineering, vol. 2018, Article ID 3730649, 16 pages, 2018.
[14] Y. Gao, M. McHenry, and B. Kerchof, "Investigation of broken cut spikes on elastic fastener tie plates using an integrated simulation method," in Proceedings of the ASME Joint Rail Conference, Pittsburgh, PA, USA, April 2018.

[15] W. Q. Shi and C. B. Cai, "Influence of slab track fastener failure on track dynamic performance," in Proceedings of the 5th International Symposium on Environmental Vibration (ISEV 2011). Advances in Environmental Vibration, pp. 686-692, Chengdu, China, October 2011.

[16] V. N. Dinh, K. D. Kim, and P. Warnitchai, "Dynamic analysis of three-dimensional bridge-high-speed train interactions using a wheel-rail contact model," Engineering Structures, vol. 31, no. 12, pp. 3090-3106, 2009.

[17] W. M. Zhai and C. B. Cai, "Train/track/bridge dynamic interactions: simulation and applications," Vehicle System Dynamics, vol. 37, no. 1, pp. 653-665, 2002.

[18] W. M. Zhai, H. Xia, C. B. Cai et al., "High-speed train-trackbridge dynamic interactions-part I: theoretical model and numerical simulation," International Journal of Rail Transportation, vol. 1, no. 1-2, pp. 3-24, 2013.

[19] W. Zhai, Z. Han, Z. Chen, L. Ling, and S. Zhu, "Train-trackbridge dynamic interaction: a state-of-the-art review," Vehicle System Dynamics, vol. 57, no. 7, pp. 984-1027, 2019.

[20] S.-H. Ju and H.-T. Lin, "Experimentally investigating finite element accuracy for ground vibrations induced by high-speed trains," Engineering Structures, vol. 30, no. 3, pp. 733-746, 2008.

[21] H. Takemiya and X. C. Bian, "Shinkansen high-speed train induced ground vibrations in view of viaduct-ground interaction," Soil Dynamics and Earthquake Engineering, vol. 27, no. 6, pp. 506-520, 2007.

[22] X. Sheng, C. J. C. Jones, and D. J. Thompson, "A theoretical model for ground vibration from trains generated by vertical track irregularities," Journal of Sound and Vibration, vol. 272, no. 3-5, pp. 937-965, 2004.

[23] H. Xia and N. Zhang, "Dynamic analysis of railway bridge under high-speed trains," Computers \& Structures, vol. 83, no. 23-24, pp. 1891-1901, 2005.

[24] X. Sheng, M. Li, C. J. C. Jones, and D. J. Thompson, "Using the Fourier-series approach to study interactions between moving wheels and a periodically supported rail," Journal of Sound and Vibration, vol. 303, no. 3-5, pp. 873-894, 2007.

[25] S. L. Grassie, M. J. Saxon, and J. D. Smith, "Measurement of longitudinal rail irregularities and criteria for acceptable grinding," Journal of Sound and Vibration, vol. 227, no. 5, pp. 949-964, 1999. 


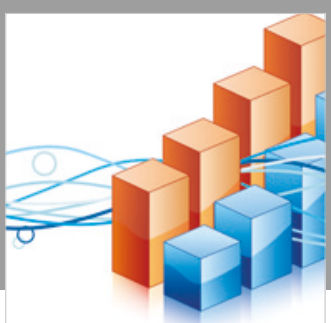

Advances in

Operations Research

\section{-n-m}
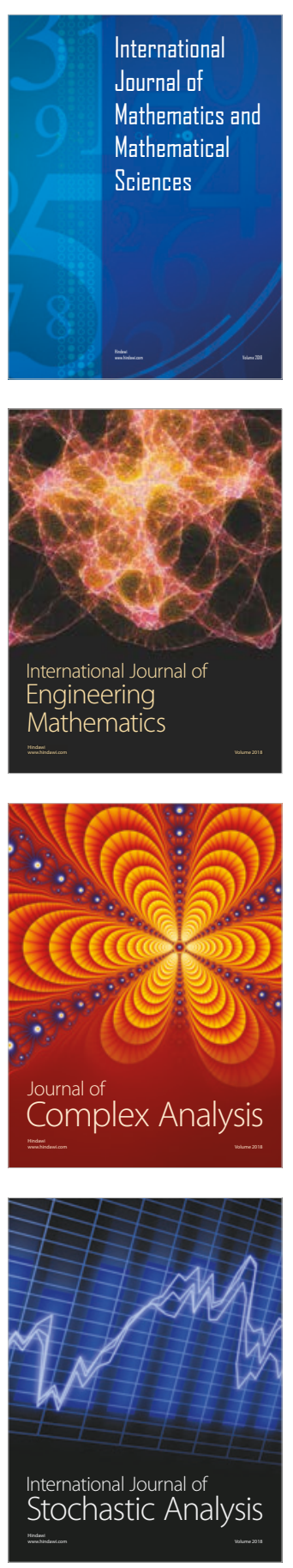
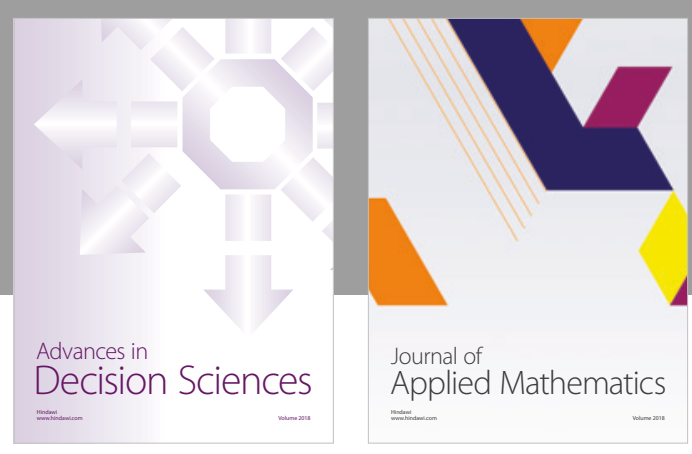

Journal of

Applied Mathematics
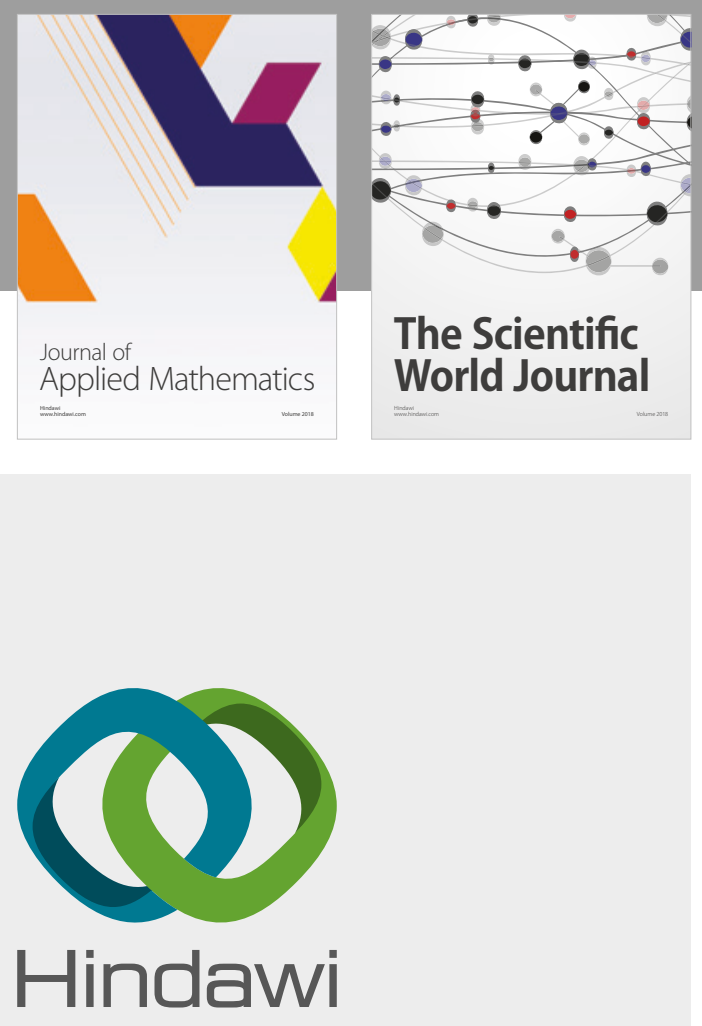

Submit your manuscripts at

www.hindawi.com

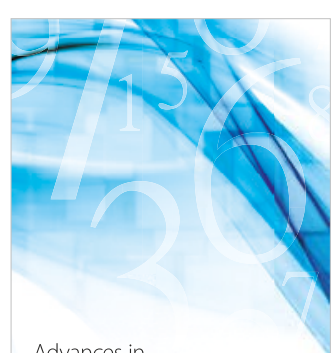

Advances in
Numerical Analysis
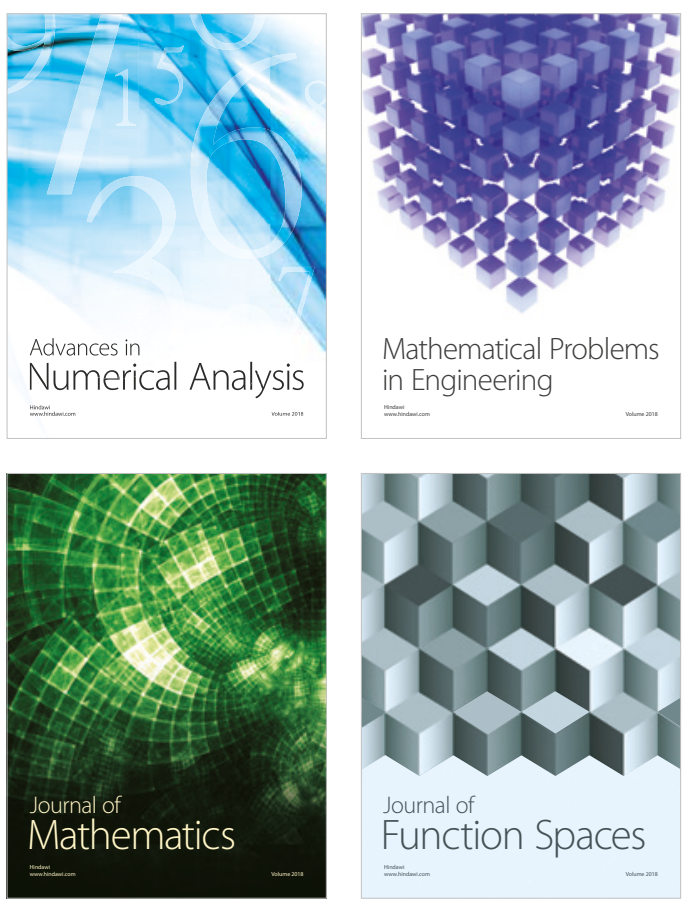

Mathematical Problems in Engineering

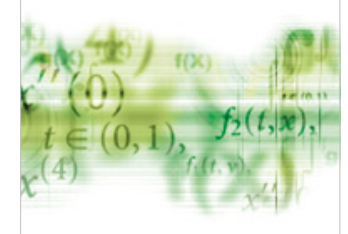

International Journal of

Differential Equations

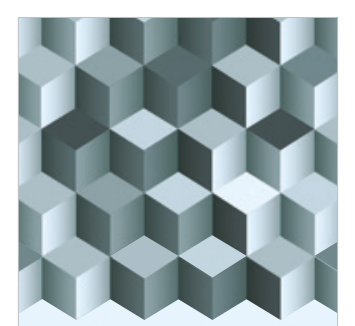

Journal of

Function Spaces

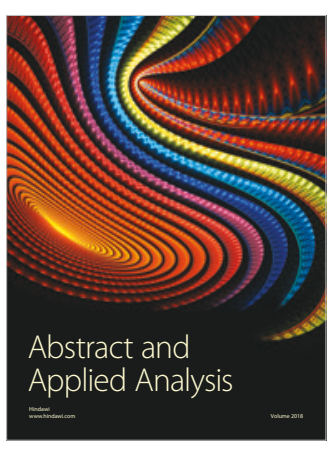

The Scientific

World Journal

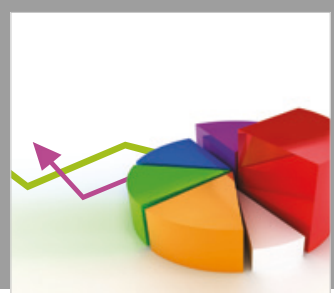

Journal of

Probability and Statistics
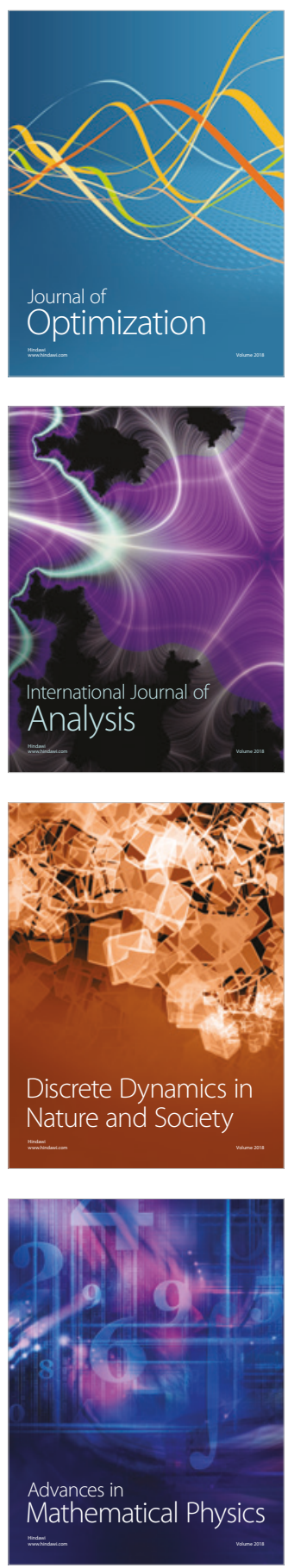